The ET column is where we ask people in the know - academics, broadcasters, educators, linguists, teachers and others connected with English worldwide - to write a column for the journal on issues of controversy, debate, work in the field, and matters of topical and immediate interest.

\section{Lookalike language}

\section{JAN BLOMMAERT}

When a language moves across the world, it does not move through empty spaces. It moves through spaces already filled with linguistic and semiotic codes, their norms and expectations, and their patterns of valuation and evaluation. And mobility, thus, affects mobile languages - most immediately through this phenomenon for which we use that old notion of 'accent'. English, of course, is learned and used with an accent all over the world now, in both spoken and written forms. There is accent in writing, too: influences from existing scripts, local forms of pronunciation of English words, locally dominant pragmatic or poetic patterns projected onto English. English, then, is quickly absorbed into the sociolinguistic system and is adapted to it.

The results of such adaptations can be seen in thousands of examples circulating on the Internet, of 'funny English' or 'Engrish', often taken from Asian public sites. Many of us have seen those; in fact I am convinced that many of us drift onto websites documenting 'funny English' after long and tough days on the job, when the cold wind is blowing outside and everything in the world seems to go wrong. We find intensely entertaining things there, and even our professional familiarity with such things will not prevent us from bursting into roaring laughter when we read 'Welcome to my erection campaign' on a Japanese politician's website or 'Too drunk to fuck' on the T-shirt of a young Thai boy.

The fact is that English in the world often appears in forms and formats that challenge our understanding of language, not just of English. English is widely used by people who have no active competence in it, or whose degree of fluency in the language precludes an accurate understanding of what they have printed on their bodies. Language, then, is not 'language' in the conventional sense of a formal system by means of which propositional meanings are transmitted. It is used emblematically, as a mere graphic sign exuding mysterious associations with the cool and the sophistication of the West, with the idea of global mobility and the universal stardom that only English-speaking people appear to have access to. English on a T-shirt then somehow becomes the equivalent of a poster of Justin Bieber or Madonna in someone's bedroom: it is an aspirational object, a projection of dreams and fantasies that revolve more around the elevated position of the object in a symbolic stratification - Justin Bieber as the universal teenager icon of the moment - than around the actual person. Very few of those who behold Justin Bieber's image on their bedroom walls will ever meet him, let alone get to know him. The Justin Bieber they adore is in actual fact their own image and understanding of 'Justin Bieberism': an ideal, a utopia, something that concludes a prayer before bedtime. Similar things happen to English in many parts in the world.

The English that people adore, admire and aspire to is, to the large majority of the world's population, beyond their reach. Realistically, a black child in a township near Cape Town will never acquire the kind

JAN BLOMMAERT is
Professor of Language,
Culture and Globalization
and Director of the Babylon
Center at Tilburg University,
The Netherlands, and
Professor of African
Linguistics and
Sociolinguistics at Ghent
University, Belgium. He


of English that earned Nobel Prizes for his/her fellow South Africans Nadine Gordimer and J. M. Coetzee. Yes, they can get English, but not that English. Globalization has in fact turned English into a global symbolic restratifier, a semiotic item that adds new layers of exclusiveness to sociolinguistic systems already marked by profound inequality in their patterns of distribution and accessibility. Wherever English occurs, it quickly occupies the top of the symbolic pyramid of social and cultural diacritics. Those who have it are almost invariably elites who can entertain realistic dreams of transnational mobility and success; those who don't have it are aware of the function of English as a gateway out of the ghetto, the favela or the township, and they project such aspirations of upward and outward mobility onto the bits of English they can acquire.

Such bits of English, as we saw, are sometimes not really English. Their function is not to express coherent linguistic meanings through the system of English. It is, rather, to show and display an awareness of the potential social capital contained in forms and shapes connected to English. My Tilburg research team have for some years now been investigating such aspirational and emblematic displays of language, and my colleague Xuan Wang at some point coined the term 'lookalike language' for them. Items of this type appear to satisfy one defining criterion : they sufficiently look like English, even if the English they display makes no sense at all linguistically.

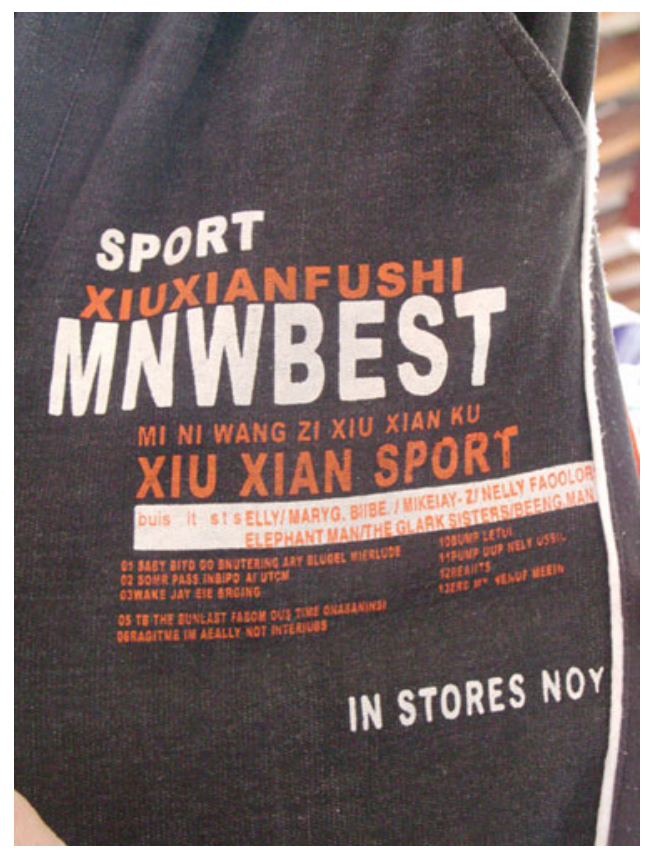

Figure 1. 'Soup of Words' () Jan Blommaert 2011.
The presence of an 'English-looking' script forming English-looking words is often enough to satisfy the demand. Thus, Figure 1 shows what might best be described as a soup of words, of English-looking words, printed on a pair of jogging trousers.

We read cryptic things such as 'MNWBest' and 'In Stores Noy'; we also see a sequence of what looks like celebrity names printed back to back:

\section{ELLY/MARYG.BIIBE/MIKEJAY-Z/NELLY FAOOLOR ELEPHANT MAN/THE CLARK SISTERS/ BEENG.MAN}

And we see quite a bit of text written in roman script and vaguely reminiscent of 'English': '01 baby diyo go bnutering any blugel mierlude'.

The impression we get here is that the printer pooled and used any form remotely known or recognizable as 'English' in an attempt not to create a readable English text but to create emblematic 'Englishness' - something that looks sufficiently like English to be recognized as English in the local context. Never mind meaning.

This can count as English in Lijiang, a small tourist town in the Southwestern province of Yunnan, China. China, as we know, is significantly more central in the world of business and finance than in the world of English; and Lijiang is definitely the periphery of China. English is a very rare commodity in such places, hard to acquire and hard to develop and use as a medium of communication. Yet, people know the emblematic value of English, and this kind of lookalike English is widely used and displayed. In a classic sociolinguistic fashion, such displays are not random. We find them whenever items or places need to be flagged as posh, expensive, better-than-normal, new, international and aimed at the affluent and the young. Thus, a shop where old-fashioned farmers' and workmen's clothes are sold - Mao-style jackets, simple cotton shirts, slacks and caps - shows no inscriptions in English at all; but around the corner, a rather more upmarket boutique targeting fashionable young customers calls itself "Panarybody" (see Figure 2).

It did take me a while before I had established that 'panary' stands for 'products that have to do with bread'. It's a nice and exclusive word that has a fine euphonic rhythm to it. It is connected to 'body' here, so 'panarybody' might be understood as 'a body that is related to bread'. Completely puzzling, given the nature of the shop, but distinctly different in total semiotic effect from the working-class textile shop selling Mao jackets. The Panarybody boutique is an entirely different place inviting different audiences and offering different adjectives to the commodities sold there. Whoever buys jeans or T-shirt there should 


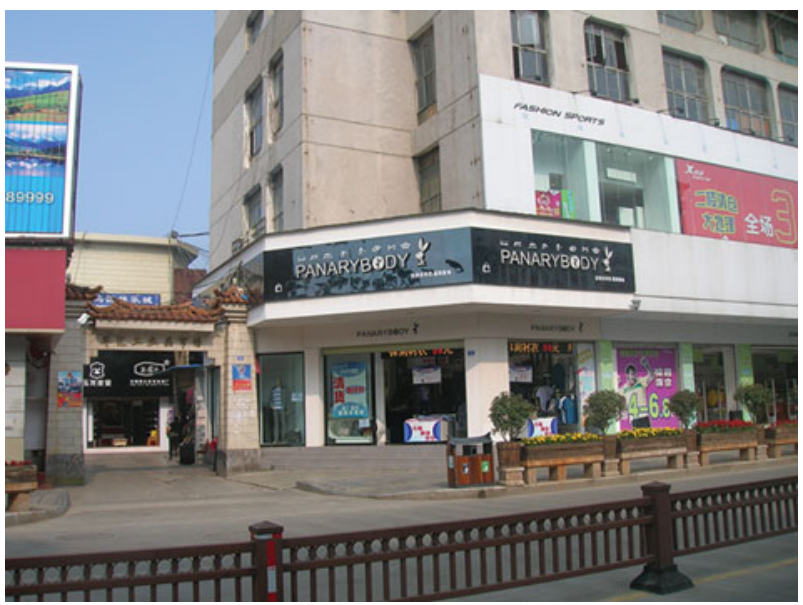

Figure 2. 'The Panarybody Store' @ Jan Blommaert 2011.

feel connected not with Kunming (the provincial capital), but with London, Milan or New York. The imitation Playboy bunny sign adds a powerful global pointer, a kind of semiotic intensifier, to this.

We have hundreds of examples of such lookalike language from all corners of the world - the peripheries of English are broader and more fragmented than Braj Kachru's Outer and Expanding Circles lead us to suspect. In fact, lookalike language is the mode of appearance and of use of an immense amount of English in the world. We tend not to take it too seriously - and prefer to use it as a profoundly amusing sidekick in our field of study - but we should consider it as a fundamental part of the phenomenology of language in the real world. The people designing such lookalike English have hardly any linguistic competence in the language; their linguistic knowledge of English is often nil. But their social knowledge of English is massive and accurate. They know about this magic language, and they know the magic it can perform. They know its indexical and emblematic potential, and they also know that even a tiny bit of (what looks like) that language can set them apart from others, create distinction in Bourdieu's sense - for within their local sociolinguistic system, very few people would be able to come to such signs with a fully developed competence in the language. Very few local people, thus, would be able to walk into the shop and say: 'Panarybody is a nonsense word; you're making a fool of yourself.'

Languages, thus, exist in areas where they are not understood as linguistic signs but still have wide currency and recognizability as emblematic signs. This is why some young people in Western Europe walk around with Chinese characters tattooed on their bodies, the meaning of which is unknown to them. For all it matters, the sign on their shoulder could read 'Two very cold beers please.' That is not the point - the point is the imagery of exoticism and Oriental mystery it articulates. It is also why a very expensive chocolate shop in central Tokyo chose 'Nina's derrière' as its name. This potentially catastrophic misnomer (imagine offering someone a chocolate obtained from 'Nina's bum') still articulated the chic and sophistication of 'Frenchness' - an indexical complex scoring even higher than English in the symbolic stratifications of contemporary consumership in Japan and drawing on materials distantly connected to a language almost universally unknown in Japan.

The use of language in globalization is not predicated on knowledge of its linguistic system. Mobile languages enter spaces in which the language cannot become a 'real' language but can lead a busy and successful life as an emblematic object of great social significance. Realizing this evidently opens up a wide space of theoretical and methodological inquiry, involving crucial questions on the nature of language, its functions and its rules of use. Lookalike language can be dismissed in a variety of ways, as 'bad English', as 'deeply nonnative English' and so forth. That is fine. But we cannot afford to neglect it as language, as one widespread mode of occurrence of language, surely not when we see how important its emblematic functions are for its users and how significant the investments are that such users make in their use. Emblematic English is at the core of the phenomenology of English as a global language. 